\title{
H2020 - RentalCal - European rental housing framework for the profitability calculation of energy efficiency retrofitting investments
}

\author{
Joseph-Alexander Zeitler \\ International Real Estate Business School, University of Regensburg, \\ Regensburg, Germany
}

\begin{abstract}
Purpose - Most of the European apartment blocks are rental units of which the majority needs major refurbishments in upcoming years to achieve climate goals. On the other hand, it is still difficult for property owners to evaluate the profitability of energetic retrofitting investments. The purpose of this paper is to contribute to the situation by forming a standardized framework and tool to calculate profitability of energy efficiency investments throughout Europe.

Design/methodology/approach - From a European perspective, several different areas of interest (technical, legal, institutional and financial) have been screened to develop an extensive compendium. This has been performed by literature research and several national surveys. Based on these findings, an online-based tool for profitability calculation has been developed to support the decision-making process of each individual, regardless his knowledge on energy efficiency.

Findings - This paper provides a short overview on main investment barriers in Germany. It is found that both market conditions and information deficits harm energy efficiency investments. Frequently, the decisionmaking process is found difficult due to inflexible regulations and lack of knowledge. This dramatically reduces market incentives that are already in place. Most often, the investor user dilemma is seen as the main investment obstacle. In this context, transparency and reliability are found to trigger energy-efficient investments.

Practical implications - Findings are used to identify best practice examples and to assess their transferability to other markets and countries. Innovative solutions have been extracted to improve the overall investment climate.
\end{abstract}

Originality/value - The paper contributes to a sound foundation for energy-related investments and the fulfillment of EU reduction targets.

Keywords Energy efficiency, Rental housing, Climate goals, Investor user dilemma, Profitability calculation, Retrofitting investments

Paper type Research paper

The following findings are based on a three-year European Union funded project, conducted by a consortium of eleven institutes and universities in eight countries, including several German partners and other institutions, such as the University of Cambridge. The general focus of this project is to improve target group specific knowledge and facilitate investment decisions on energy efficiency retrofitting opportunities. In a first step, market conditions

(C) RentalCal Consortium. Published by Emerald Publishing Limited. This article is published under the Creative Commons Attribution (CC BY 4.0) licence. Anyone may reproduce, distribute, translate and create derivative works of this article (for both commercial and non-commercial purposes), subject to full attribution to the original publication and authors. The full terms of this licence may be seen at http://creativecommons.org/licences/by/4.0/legalcode

The author acknowledges the entire RentalCal Consortium for their input, helpful comments and suggestions which helped improving the paper. All participating organizations can be displayed at the official project website: www.rentalcal.eu/the-consortium. Special thanks is given to the H2020 program of the European Union for funding this project under EASME (649656 - RentalCal - H2020EE-2014-2015/H2020-EE-2014-3-MarketUptake).

Received 20 December 2017 Accepted 20 December 2017 rental housing framework 
JPIF

36,1

for energy efficiency upgrades in the consortium European countries were surveyed to provide specific information to residential real estate owners about profitable and cost optimal energy efficiency investments. Best practices in these countries were identified, and their transferability to other markets and countries was assessed.

\section{Energetic energy efficiency retrofitting in rental housing - a low-hanging fruit} to achieve climate protection

Both experts and politicians agree that real estate-related climate change mitigation measures are relatively cost efficient in comparison to other industries. Also, the positive impact of upgrading the real estate stock is potentially very large, given the enormous number of existing buildings that could benefit from higher efficiency. As a consequence, both home builders and the broader real estate industry in Germany have constantly been committed to reaching energy policy goals by steadily tightening energy efficiency requirements for new construction $(\mathrm{EnEV})$ and other regulations.

National climate protection goals derive from the Paris Climate Agreement targets. Additionally, German climate protection goals are embedded into relevant regulations on the EU level. Already in 2007, the European Commission has set up a package of mandatory legal regulations (Climate \& Energy 2020) pursuing the following three main goals: reducing $\mathrm{CO}_{2}$ emissions by 20 percent (base year 1990), increasing the use of renewable energy and energy efficiency by 20 percent each until 2020 (base year 1990). On October 14, 2016, the European Council agreed on reducing them by 40 percent until 2030. The goals set up by the EU for 2030 were presented to the United Nations as the European contribution (INDCs) to meeting the global climate treaty goals. Subsequently, the European Union has set even more ambitious goals for 2050. These include a decrease of greenhouse gas (GHG)-emissions by 80-95 percent until 2050 (base year 1990).

Focusing on the building sector - volume and cost efficiency promise big savings According to the Buildings Performance Institute Europe, 97 percent of buildings in the EU need to be upgraded to decarbonize the building stock. Buildings account for 40 percent of the entire energy consumption of Europe. Residential buildings account for 75 percent of this building stock. The German real estate sector is responsible for one-third of all national GHG-emissions, thus taking a major role in climate protection policy. The aim is to achieve climate-neutral buildings by 2020 and a nearly climate-neutral housing stock by 2050 . The rate of refurbishment for existing buildings is targeted at 2 percent. Even though Germany takes a pioneering role, energy efficiency modernization rates are lower than necessary in order to achieve carbon reduction policy goals in the building sector. The overall retrofit rate in Europe is around 1 percent per year.

To put the above-mentioned European goals into the German context, according to Energy Saving Ordinance regulations which are continuously tightened (most recently in 2014), thermal energy demand is to be reduced by 20 percent until 2020 (base year 2008). As of 2015, thermal energy demand was only reduced by 11.1 percent.

Additionally, studies show that annual investments in energy efficiency in the institutional rental housing industry are short of about $€ 4$ billion annually in Germany alone. With negative real rent growth rates, maybe with the exception of growing metropolitan areas, investment levels were hard to raise to the level needed to deepen retrofitting activities during the last decade. In the recent market boom, rent levels seem to adjust not only in all major urban markets but also in second-tier cities. In tandem with low capital costs, this may boost retrofitting investments in the housing sector. However, despite several grants and subsidies, incentives in the 
current low interest rate environment are as never before, which might have the opposite effect.

The existing European housing stock comprises more than 40 percent of residential buildings built before the 1960s. Most of the existing housing stock in Germany can be attributed to the Wilhelmine era of rapid urban expansion and the post-Second World War period of reconstruction and economic growth. These buildings should be subject to major lifecycle bound modernization activity. Especially, the post-war housing stock is predestinated for deep energy retrofitting. Figure 1 shows that with a share of around 55 percent, the rental housing market in Germany is one of the largest in absolute numbers in the European Union, influencing carbon balances the most. About 40 percent of the rental housing stock is property of individual private landlords, and another quarter is held by condominium associations. Therefore, these target groups need to be attracted to increase retrofit activities (Figure 1).

\section{Limited market transparency and investor knowledge harm energy efficiency retrofitting activity}

But there are still several constraints that hamper the energy efficiency refurbishment process. In general, there are two ways in which low-energy housing can be achieved: either through reducing energy consumption by cutbacks and efficiency enhancements (demand side) or through cleaner energy (supply side). Realistically, both approaches will be combined to achieve the ambitious carbon reduction targets. It is expected by the European Union that by 2020, yearly energy savings equivalent to the annual energy consumption of Italy are deliverable. This could be translated to savings of up to $€ 500$ per year on each individual energy bill, which is only possible through energy savings in living.

This reduction of energy goes hand in hand with the use of advanced technical appliances. Within the last decade, a couple of technical solutions to reduce GHG-emissions came onto the market. These range from new heating systems, like heat pumps, roof and façade insulation to triple glazing. But the acceptance and take-up of these improvements is still very low, due to an inherent lack of knowledge and transparency. Further barriers are illustrated in Figure 2. This might change quickly in Germany, due to the tremendous amount of property transmitted to younger generations. Nevertheless, the energy-efficiency gap, which represents the difference between planned, determined energy consumption, and actual consumption, respectively, will still be one of the main problems which need to be solved.

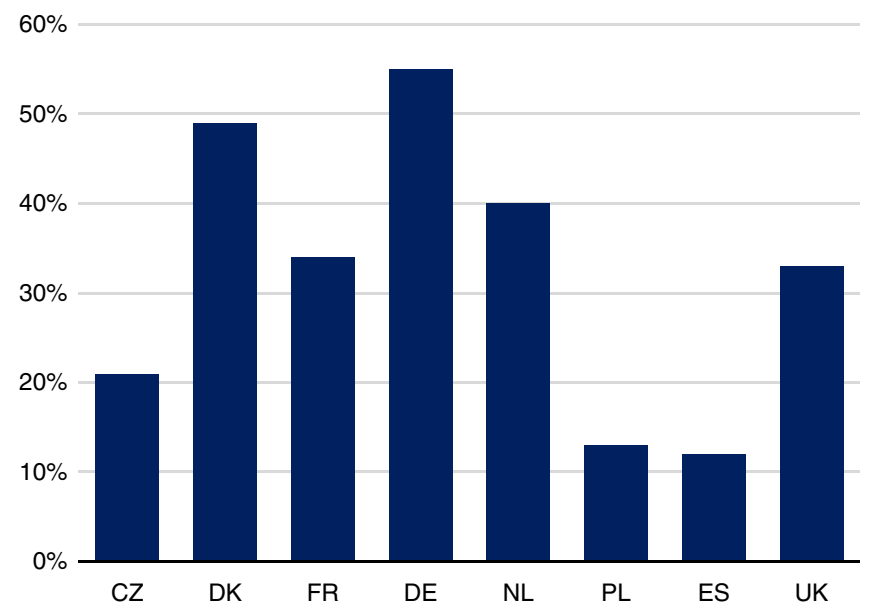

Figure 1. Share of rental dwelling units (of total housing stock) 
JPIF
36,1

128

Figure 2.

Construction-related

barriers for

investments
Figure 3.

Average cost of refurbishment per unit of saved energy (standard refurbishment)

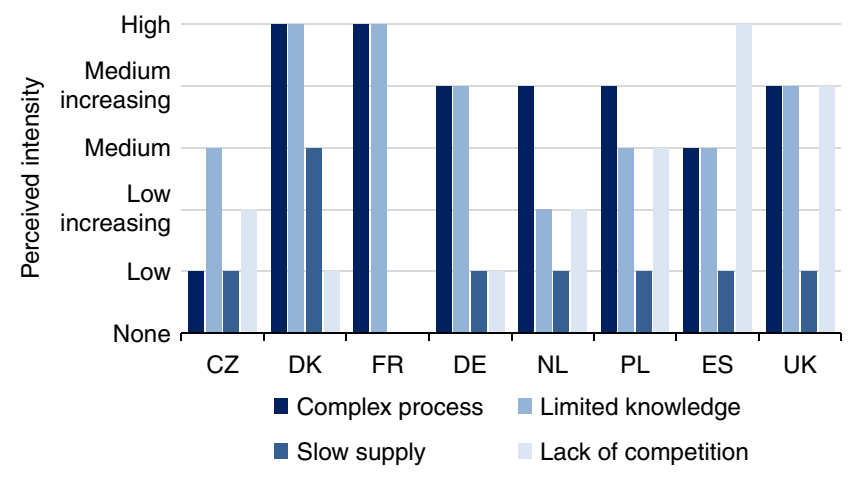

This is directly linked to the mismatch between consumption and payment of energy. Along with refurbishment processes that are perceived as complex and the requirement of specialist knowledge, this harms energy efficiency retrofitting. In addition, slow supply of construction materials and, consequently, a lack of capacity in the construction industry are observable in the market, especially in Spain and the UK. In relation to this limited supply, there is a lack of competition between service providers and therefore no incentive by suppliers to reduce prices at affordable levels. Energy savings vary depending on climate conditions, building types and the composition of refurbishment packages.

Figure 3 illustrates the possibility to save energy and relates that to the overall refurbishment costs. The figures presented in the graph are derived from data for exemplary buildings (TABULA typology) collected from project partners. It can be seen that some countries, such as Spain, have a low possibility to save energy in relation to refurbishment costs. Others, such as Germany, have lower refurbishment costs in comparison to the achievable energy level. Thus, investment costs and resulting energy savings vary widely across the mentioned countries. From the EU perspective, it is most favorable to push energy efficiency retrofitting in countries with the best value for money.

\section{Main barrier to energy investments - investor user dilemma}

Even though analysis found that institutional framework conditions in these countries regarding the constellation for decision making and motivation of investors

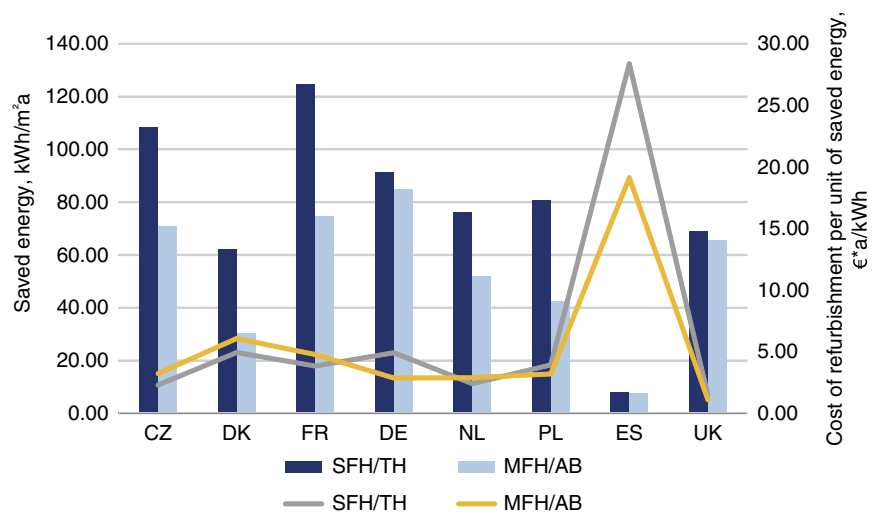


are very heterogeneous, profitability is still the main driver of implementation. Therefore, it is of most interest to show investors that such investments can generate a positive cost-benefit ratio.

Most investors are afraid of investing in energy efficiency because they fear there might not be an adequate pay-off. It has become conventional wisdom to assume that the split incentive barrier is an important barrier to the implementation of energy efficiency. The landlord usually does not pay energy bills for the tenant space and therefore has no direct financial incentive to install more expensive energy efficient measures. Still, the investor has to take on the full investment costs, and the tenant has the benefit in form of lower total rent. Not sharing the initial investment cost of energy efficiency retrofits is a significant barrier in Denmark, France and the Netherlands. On the contrary, a tenancy agreement in which the landlord pays the energy bill is in favor for refurbishment activities, but comes in Germany along with the possibility for the tenant to break the lease early (within one instead of three months). This might result in reluctance to give consent due to the time and discomfort associated with the retrofitting. Rent mechanisms like these are mainly perceived as barriers and just sometimes as facilitators of energy efficiency investments. Germany, for example, made changes to legislation in order to increase energy efficiency retrofitting activities. Nowadays, on the basis of the Civil Code, 11 percent of the energy-related investment costs for residential buildings can be recouped from the tenant via a rent increase. It can already be observed that this pushes the amount invested in energy efficient refurbishments due to fair cost-benefit sharing. Therefore, the German model might serve in other European countries as a good example. Nevertheless, energy efficiency retrofits are perceived as a secondary priority by tenants in the majority of the above-mentioned countries, with the exception of Denmark. This is due to several obstacles stated in Figure 4, especially to low and stable energy prices that are inherent. In most European countries, energy prices are not priced to support retrofitting activities as the monthly energy bill has a marginal effect on the total monthly disposable income (due to mispricing of energy) and therefore diminishes the incentive to take meaningful action. The demographics associated with each country also play a significant role in the likelihood of energy efficiency retrofits taking place. Countries with high average population age are less motivated to adopt technological changes.

\section{Green premium and non-monetary aspects must be factored into financial decisions}

Investor-related barriers are most prominent in the market, shown in Figure 5. Due to the inability to fully capitalize the green value in property value, even if energy-related investment costs can be partly passed onto the tenant, it is still uncertain whether the investment is profitable or not. Therefore, high initial capital costs are cited as a significant barrier across all countries. But whereas high initial investments are easy to integrate into

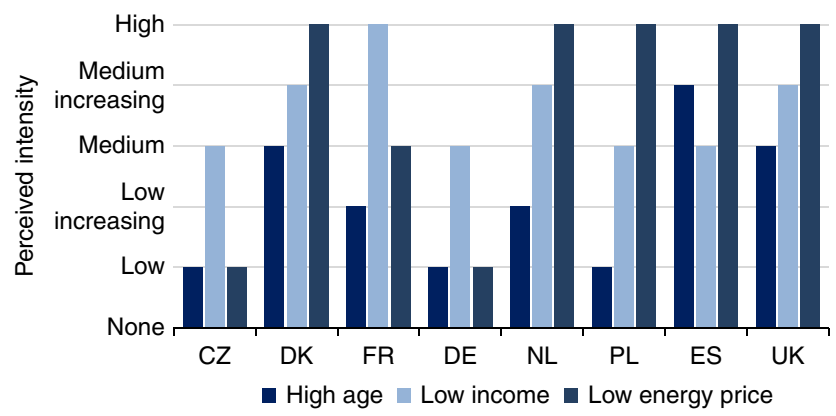

Figure 4.

Tenant-related barriers for investments rental housing framework 


\section{JPIF \\ 36,1}

130

Figure 5.

Investor-related

barriers for

investments

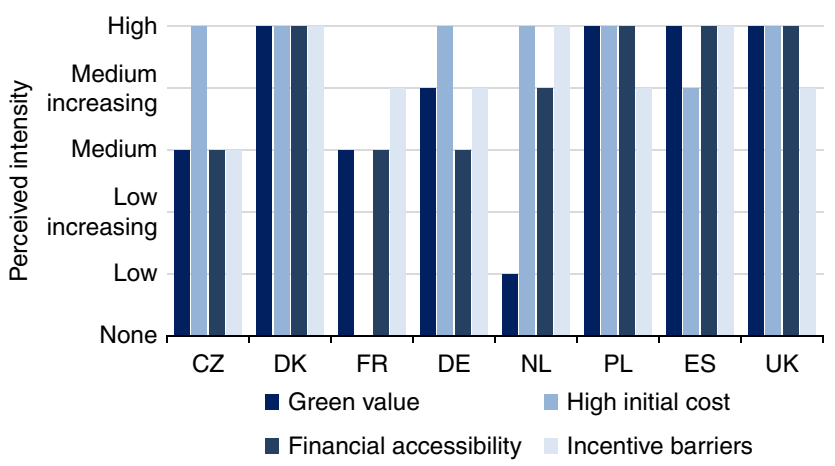

profitability calculations, a variety of other input variables that are positively affecting the economic advantageousness of a retrofit project are difficult to account for, for example, the green premium which is usually reflected in higher rents or additional sales revenue.

The RentalCal web-based tool will be provided to a wide range of users to determine the profitability of energy efficiency retrofits. The tool is suitable for different target groups, such as landlords, managers of housing companies, property manager and energy consultants. This is possible due to different input modes, which account for the specific knowledge and data availability of different user groups. For the first time, cost side and return side approach are brought together within a visualization of financial implications framework, which accounts for all relevant factors that can contribute to the viability of retrofit investments, such as depreciation and tax information. Investment in energy efficiency is still a long-time investment. Therefore, payback periods tend to exceed the thresholds set by investors. This is currently exacerbated by the ongoing internationalization of the institutional housing sector in Germany, which potentially shortens investment horizons even more.

As already mentioned, many investors question the existence of green value, even though many empirical studies demonstrated it empirically. However, green value is not only changing the expected sales value, it also has other implications. The so-called gray discount gets discussed more and more frequently as a certain level of energy efficiency, paired with social responsibility, gets recognized as market standard. Therefore, investors need to ask themselves if their assets can be still sold even those do not contribute to the overall well-being of society. Buildings that are so-called "future proof" already consider political and legislative changes concerning energy efficiency and are therefore less risky. Hence, not only profit relevant advantages should be taken into account. Energy efficiency refurbishments also provide other improvements, which cannot be put into financial terms. But still, those can push investors toward energy efficiency retrofits. This includes on the one hand, a reduced risk of rent reduction, lower vacancy rates and a lower time on the market, even though this might not be relevant for each market. On the other hand, tenants and society benefit from the positive effects on local air quality, noise protection and the direct impact on inhabitants' health. In the end, by making energy-efficient improvements in apartments, investors are acting in their own economic self-interest and the interest of the entire society.

There is still need for further research in this field. While the barriers to achieving higher energy efficiency in the private rental sector are well understood, it is difficult to provide a definitive set of new policy recommendations at this point. Continuous evaluation of existing programs is essential to establish a framework for future policy considerations. Increased stringency of existing EU legislation, continuous evaluation of achievements of 
national objectives and the establishment of national roadmaps, which are tailored toward demographic capabilities, are essential. Sound financial incentives are likely to spark action, evident from national findings in France and Germany.

First results from RentalCal can already be downloaded on the project website www.rentalcal.eu. The entire project and the tool, more particularly, should contribute to the fulfillment of EU reduction targets.
European

rental housing framework

\section{Corresponding author}

Joseph-Alexander Zeitler can be contacted at: joseph-alexander.zeitler@irebs.de 